\title{
Recursos expresivos y literarios en el huayno ancashino
}

\author{
Expressive and literary resources in the Ancash huayno \\ Félix Julca Guerrero \\ Universidad Nacional Santiago Antúnez de Mayolo, Ancash, Perú \\ Contacto: fjulca@unasam.edu.pe \\ https://orcid.org/0000-0001-5637-5440
}

Laura Nivin Vargas

Universidad Nacional Santiago Antúnez de Mayolo, Ancash, Perú

lnivin@unasam.edu.pe

https://orcid.org/0000-0001-5169-3597

\begin{abstract}
Resumen
Este artículo describe y analiza, desde la perspectiva lingüística y literaria, los recursos expresivos, literarios y lingüístico-comunicativos en el huayno ancashino, una manifestación tradicional andina en la que se combinan poemas populares quechuas y la música tradicional rural. El estudio de fue nivel descriptivo y abordado con enfoque cualitativo. La data recolectada demuestra que el arte verbal quechua en el huayno ancashino evidencia el uso de diferentes recursos léxicos, expresivo-comunicativos y literarios para manifestar diferentes aspectos de la vida, la muerte y el amor con sus múltiples facetas. En la composición de los versos se evidencia procesos de resemantización y nuevos giros semánticos que adquieren las palabras y expresiones, uso de préstamos lingüísticos y alternancia de códigos, presentadas poética y metafóricamente. De esta manera, el huayno ancashino interpreta poética y artísticamente el sentir y las vivencias de sus gentes y se constituye en la riqueza cultural ancashina.
\end{abstract}

Palabras claves: Quechua; Arte verbal; Huayno; Recursos lingüísticos y literarios

\begin{abstract}
This paper describes and analyzes, from the linguistic and literary perspectives, the expressive, literary and linguistic-communicative resources in the Ancash huayno, a traditional Andean manifestation in which Quechua folk poems and traditional rural music are combined. The research was descriptive and approached with a qualitative approach. The data collected demonstrates that the Quechua verbal art in the Ancash Huayno evidences the use of different lexical, expressive-communicative and literary resources to manifest different aspects of life, death and love with its many facets. In the composition of the verses it is evident processes of resemantization and new semantic turns that acquire words and expressions, use of linguistic loans and code switching, expressed poetically and metaphorically. In this way, the Ancash huayno songs poetically and artistically interprets the
\end{abstract}


feelings and experiences of its people and constitutes the Ancash cultural richness.

Key Words: Quechua; Verbal art; huayno; Linguistic and literary resources

Recibido: 02.10.19

Aceptado: 12.11.19

\section{Introducción}

En una sociedad como la peruana, marcada por las desigualdades socioeconómicas, la discriminación y la diglosia, se han creado, históricamente, muchos mitos, falacias y prejuicios en contra del quechua y sus hablantes. Así, en el imaginario regional y nacional está ampliamente generalizada la idea de que el quechua es una lengua «pobre», «atrasada» y «defectiva» debido, entre otras cosas, a su supuesto limitado vocabulario que no alcanza para transmitir la modernidad, el pensamiento abstracto, la literatura, la ciencia y la tecnología, sino solo para la comunicación informal, a nivel familiar, amical y rural (Parker, 1972; Julca, 2015; Julca \& Julca, 2016). No obstante, los estudios recientes han demostrado que el quechua, como cualquier otro idioma natural del mundo, tiene suficientes recursos lingüísticos, estilísticos, literarios ${ }^{1}$ y pragmáticos para transmitir no solamente las prácticas y valores del mundo natural y cultural en el que los quechuas se desenvuelven, sino también el pensamiento moderno, abstracto, literario, académico y científico (véase Itier, 1999; Julca, 2003, 2009b, 2015; Hurtado de Mendoza, 2009; Julca \& Julca, 2016). Al respecto, Chávez (1998) señala que el quechua tiene un potencial poético donde las palabras registran mayores posibilidades polisémicas que el castellano. Además, "el uso de sufijos le da la flexibilidad que la hace más adecuada a los requerimientos sentimentales y permite construir metáforas, comparaciones y toda clase de figuras literarias" (p. 169).

En el mundo andino, a través del tiempo, se ha desarrollado diferentes manifestaciones literarias asociadas a la matriz cultural andina. Desde la invasión española, en paralelo a la literatura oficial académica, se ha seguido practicando las otras formas propias de literatura andina quechua con gran valor estilístico, 
poético, lingüístico y comunicativo transmitidas oralmente. Por ello, Toro (1990, p. 14) refiere que en el proceso de la literatura de un país no solo se debe contar con los literatos y sus obras, sino también con las creaciones de autores anónimos y tradiciones orales, debido a que ellos transmiten con fidelidad la vida experimentada de los pueblos. En esa perspectiva, Cornejo (1994) observa diferentes manifestaciones literarias en el mundo andino desarrolladas a través de la oralidad y la escritura, y postula la tesis de las "literaturas heterogéneas". Dicha heterogeneidad también se manifiesta en la literatura andina quechua, pues desde la antigüedad hasta tiempos actuales se ha practicado diferentes manifestaciones y géneros literarios como el lírico, narrativo y dramático trasmitidos oralmente como parte de una actividad colectiva al compás de la música, la risa, del llanto, del horror y de la alegría de sus oyentes y actores (véase Toro, 1990; Bendezú, 2003; Espino, 2010; Julca \& Julca, 2016). Por tanto, en el mundo andino quechua, siguiendo la postura de Cornejo (1994, p. 25) "heterogeneidad en las literaturas andinas", no podemos hablar de literatura en singular, sino de literaturas en plural. Además, para entender la dinámica literaria andina es importante articular las categorías teóricas (totalidad contradictoria y heterogeneidad) y comprenderlas en su desarrollo histórico ( $c f$. Westphalen, 2019).

Las literaturas andinas quechuas se han caracterizado, generalmente, por ser orales y anónimas, y transmitir los diferentes matices de las vivencias del hombre del Ande. Estas literaturas han sido denominadas por Vansina (1968) como "La tradición oral", Godenzzi (2005) "Tradición oral andina”, Bendezú (2003) "Literatura quechua”, Espino (2010) "La literatura oral o la literatura de la tradición oral", entre otras. Las literaturas andinas quechuas además de cumplir la función de trasmitir las actividades y vivencias de los hombres del Ande (canto, danza, trabajo agrícola y ganadera, ritual religioso), también cumplen la función poética-literaria conservando la palpitación de la vida de sus creadores y de sus intérpretes que vivieron y actualizaron las composiciones, al compás de la música, de la danza, de la risa, del regocijo, del llanto, del pánico y de la alegría de sus oyentes y actores (Bendezú, 2003, p. XVIII). Las composiciones literarias en quechua y también bilingües (quechua y castellano), como en el caso 
de los huaynos en general y el huayno tradicional ancashino en particular son muy elaboradas, sonoras y de una belleza y complejidad incomparables.

Una de las manifestaciones poéticas más comunes en los Andes peruanos en general y ancashino en particular, es el huayno (wayñu o waynu). El primer cronista indio, Guamán Poma de Ayala ([1614] 1993), concibe al huayno como una forma de parentesco ritual. Arguedas (1940) refiere que el wayno es la danza en que se vuelca libremente el regocijo y la voluptuosidad popular y la que recoge la inspiración del pueblo quechua en todos sus matices. Según el padre Jorge Lira (1982), el wayno, waynu o wayñu es un "coro o estrofas que se repiten después de cada pie de verso; danza o baile característico al son de la música de ese nombre" (p. 327). Por su parte, Montoya (2013) refiere que "El wayno es identificado por su particular melodía de base pentafónica y ritmo melódico binario con base quechua para oír, cantar, bailar" (p. 159). Además, añade que "en tiempos incas el wayno fue un baile-canción de amor de una pareja y, hoy, es más que un baile, una canción para expresar todo tipo de sentimientos y, también, una especie de crónica de todo lo que ocurre" (p.190). Asimismo, Escobar y Escobar (1981) señalan que "El wayno es una composición poética para ser cantada al son de una tonada musical que también se interpreta con algún o algunos instrumentos musicales y que se baila por parejas a un compás que varía de una región a otra" (p. 11). En suma, el huayno es una manifestación cultural andina donde se combinan las artes de la literatura, la música y la danza².

En el contexto más regional, el huayno es concebido como una composición poético-literaria y musical más común y popular en la zona andina de Áncash. Den Otter (1985) sostiene que el huayno es el género musical y danza más popular en el Callejón de Huaylas (Áncash). Por su parte, Rosales $(1991,2009)$ y Julca $(2009 b)$ señalan que, el huayno es la manifestación artística tradicional andina que consiste en una combinación de poemas populares quechuas y la música tradicional rural. Este género poético y musical andino es la manifestación popular típica por excelencia que tiene presencia en las fiestas dominicales, patronales y familiares. En las últimas décadas, principalmente, a 
partir de la década de los 70 con la migración del campo a la ciudad, el huayno ha invadido irreverentemente plazas, calles, bares, salones, peñas folclóricas y concentraciones ceremoniales en las zonas semiurbanas y las propias ciudades provincianas (Rosales, 2009) no solo de los Andes, sino también de la costa (Julca \& Smith, 2005). Socialmente, el huayno es la expresión de los campesinos, obreros, artesanos, pequeños comerciantes y los hijos de estos, que gradualmente, han alcanzado niveles económicos sobresalientes (Rosales, 1991, p. 28; 2009, p. 35). Por su parte, Julca y Smith (2005) sostienen que el huayno, también ha sido adoptado por los mestizos e hispanohablantes de las zonas urbanas andinas. Así, ninguna fiesta (bautizo, matrimonio, aniversario u otros) puede concluir sin que se haya cantado y bailado un huayno. Asimismo, el huayno es reproducido en las ciudades de la costa y otras regiones por los migrantes de las zonas andinas. Por consiguiente, la cobertura del huayno es amplia tanto en el hombre del campo como en el suburbano y el de las ciudades.

El huayno ancashino tradicional también llamado chuscada por su procedencia humilde, popular, graciosa y pícara interpreta el sentir y vivencias de sus gentes y se constituye en la riqueza cultural ancashina (Rosales, 1991, 2009, Den Otter, 1985). El huayno ancashino tradicional se diferencia del huayno moderno $^{3}$ por desarrollar un espectro temático muy amplio relacionado con las diferentes actividades, sentimientos, sueños, alegrías, tristezas del hombre del campo. Estas composiciones son, mayormente, anónimas y han sido interpretadas por los canta-autores como: la Pastorita Huaracina, la Princesita de Yungay, la Estrellita de Pomabamba, el Gorrión Andino, el Jilguero del Huascarán, Juan Rosales, la Huaracinita, entre otros. Actualmente, pocos siguen con esta tradición artística poético-musical, entre ellos podemos nombrar a la Chinita Cordillerana, Anita Fajardo 4 , La Marquinita, Azucena Kantarina, César Torres (El Huerfanito de Yungay), Nelly Torres, y algunos otros. La parte musical del huayno ancashino tradicional es interpretada, principalmente, con instrumentos como la mandolina, la guitarra, el violín, el acordeón y la quena. El canto poético de los mensajes es compuesto, mayormente, con recursos estilísticos y poéticos especiales basados en formas sonoras del lenguaje y el carácter aglutinante de la lengua quechua que 
van en sintonía y ritmo de la música (Julca \& Smith, 2005; Julca, 2009b, 2009c; Julca \& Julca, 2016). En suma, en Áncash, el huayno ha llegado a constituirse en un referente cultural, que además de ser un juego artístico, poético y musical, involucra todo un pensamiento y una forma de vida.

En este marco, antes que realizar un estudio de la música y danza, nos propusimos investigar el uso de recursos expresivos, literarios y lingüísticocomunicativos en el huayno ancashino tradicional, temática aún poco estudiada en el ámbito regional. Para ello, nos formulamos las siguientes preguntas de investigación: ¿Cuáles son los temas preferidos en el huayno ancashino tradicional?, ¿Qué figuras literarias y recursos estilísticos se usa en el huayno ancashino tradicional? y ¿Qué mecanismos y recursos lingüísticos y pragmáticos se usa para comunicar mensajes estética y literariamente en el huayno ancashino tradicional? Para responder a estas preguntas se realizó una investigación básica de nivel descriptivo abordada bajo el enfoque cualitativo utilizando, principalmente, la técnica documental para el acopio de datos. En suma, con esta investigación nos propusimos rastrear la producción poético-musical del huayno ancashino tradicional, para luego describirla y analizarla desde las perspectivas literaria y lingüística.

\section{Métodos y materiales}

Para una aproximación al estudio sobre el uso de recursos expresivos y literarios en el huayno ancashino tradicional se optó por el enfoque cualitativo de la investigación con la finalidad de describir y analizar abarcando lo ético hasta llegar a lo émico del asunto. En dicha perspectiva, el trabajo de investigación se enmarcó en los casos de los estudios descriptivos donde antes que las hipótesis fueron las preguntas que guiaron la investigación. Fue descriptivo porque su propósito fue pesquisar, describir y analizar las producciones literario-musicales del huayno ancashino compuestas en lengua quechua, así como en castellano y también en forma mixta o bilingüe en quechua y castellano, a luz de los aportes de la crítica literaria, lingüística descriptiva y antropología lingüística.

El universo de estudio comprendió, prioritariamente, la región Áncash, 
pero también tuvo un alcance nacional para el recojo de la información. Para el acopio de datos se utilizó la técnica de análisis documental; y como instrumento, la ficha de registro de información tanto de producciones originales en quechua, así como de estudios al respecto. El procedimiento que se siguió en el desarrollo de la presente investigación comprendió tres etapas: Primera, formulación del proyecto de investigación. Segunda, recopilación de datos destinada principalmente a la revisión de la literatura y a la recopilación de información básica, así como a la pesquisa de discos, casetes, CDs de canciones y cancioneros. Las transcripciones de las canciones se realizaron utilizando el alfabeto estandarizado del quechua (Resolución Ministerial No 1218-85-ED, ratificado en los Acuerdos de Cieneguilla, 2014). Así como teniendo en cuenta las pautas establecidas en el Manual de Escritura del Quechua Central (Julca, Espinoza y León, 2018). Tercero, procesamiento y análisis de datos que empezó con el procesamiento físico y concluyó con el procesamiento analítico de los datos presentados en las secciones de resultados y discusión.

\section{Resultados}

La data sobre el huayno ancashino tradicional comprendió un total de 95 canciones que incluye huaynos en (1) quechua, (2) castellano y (3) quechua y castellano. Estas muestras del huayno ancashino tradicional fueron obtenidas de CDs, DVDs, cancioneros; asimismo se hizo un registro de canciones de los programas radiales matutinos de Huaraz y otras ciudades del Callejón de Huaylas. Además, los datos recopilados han sido contrastados con las antologías del huayno ancashino del canta-autor, poeta y estudioso Efraín Rosales (1991, 2009), así como las compilaciones y cancioneros de Maguiña (s.f.), Instituto Nacional de Cultura, filial Huaraz (1980) y Den Otter (1985). Según los objetivos de la investigación, la data ha sido organizada en tres grupos: (a) diversidad temática, (b) recursos estilísticos y figuras literarias y (c) recursos lingüísticos y comunicativos. En cada caso se presenta fragmentos de canciones que están directamente relacionadas con el tema que se desarrolla. 


\section{Diversidad temática}

Las muestras del huayno ancashino tradicional que se presentan a continuación desarrollan una amplia cobertura temática que comunican la vida del hombre del campo, del migrante y del citadino, sus sentimientos, sufrimientos, alegrías, amoríos en íntima relación entre lo objetivo y lo subjetivo. Montoya (2013, p. 165) presenta un cuadro de selección de canciones quechuas por temas y departamentos, donde identifica los siguientes temas preferidos en el departamento de Áncash (Huaylas y Conchucos): amor, familia-orfandad, ciclo vital (soltería, matrimonio, casa nueva, muerte), naturaleza (animales, árboles, coca, sirenas, flores y ríos), religión (indígena, católica). Por su parte, Julca (2009b) identifica como temas recurrentes: el trabajo, el amor, el recuerdo, la alegría, el desengaño, el sufrimiento y la tristeza. Allí cobran singular importancia -dice Rosales (2009)- "afectos, intereses y distanciamientos (...). Pesares, esperanzas, tristezas y angustias se pintan con sumo realismo, exteriorizando sutilezas amorosas, erotismo fino y el humor catártico; donde imágenes bellas del paisaje inspiran poemas llenos de metáforas sencillas de cariño al hombre y la naturaleza" (p. 35).

La grandiosidad del hombre andino está dada por su dedicación al trabajo. El trabajo es inherente a los hombres y mujeres del campo, no en vano tienen como uno de los valores morales y principios fundamentales «ama qilla» 'no ser ocioso' (Julca, 2010) que sugiere la laboriosidad y el trabajo. Para el hombre del campo, la prosperidad está basada en el trabajo que realiza.

(1) Muchachos a trabajar

si quieren tener mujer,

acaso con el amor

se mantiene a la mujer.

('Al principio de mis amores', Anónimo)

La concepción de la unidad entre naturaleza y sociedad está presente en el huayno ancashino. La naturaleza andina está poblada por un conjunto de seres animados y no animados con quienes el hombre mantiene una comunicación, convivencia y crianza mutua. Es decir, según la concepción andina, los objetos 
de la naturaleza tienen vida, sienten, sufren, se alegran como los seres humanos, por ello son tratados por el hombre como seres humanos y se comunican recíprocamente (Julca, 2009a, 2010). Por limitaciones de espacio, en lo que sigue se presenta solo algunas muestras de la diversidad temática del huayno ancashino. En los siguientes ejemplos, en el primer caso se observa el diálogo entre el hombre y un ave (zorzal 'yukis'); en el segundo, la invocación que hace el hombre a una planta medicinal, la escorzonera:

(2) Yukis, yukis, qiri siki yukis; Zorzal, zorzal, zorzal con ano lleno de costra; tamyariptin, usyariptin, cuando llueve, cuando escampa la lluvia, ¡Por Dios! ¡Por Dios! ¡Por Dios! ¡Por Dios!

nimarqayki. Me dijiste.

('Waychaw', Anónimo)

(3) Escorzonera, yerba del campo como me dices que eres remedio.

Si eres remedio cura mis males si eres veneno quitame la vida. ('Escorzonera’, Anónimo)

Otro de los temas favoritos del huayno ancashino tradicional es el amor que es presentado en sus múltiples facetas como la correspondencia de las parejas, el lamento, la soledad, el erotismo, etcétera. El amor como una expresión de la convivencia humana es presentado como una realidad donde se entrecruzan enfrentamientos, soledades, angustias y alegrías. En lo que sigue, se anota algunos temas específicos relacionados con el amor. Por ejemplo, en la siguiente estrofa se observa el amor correspondido plenamente y es expresado con alegría la correspondencia recíproca de las manos y los labios de los amantes:

(4) Qampa makiyki, nuqapa makii Tu mano y mi mano musyanakurmi tsaripaanakun, porque se conocen se agarran, qampa shimiyki, nuqapa shimiitu boca y mi boca 
musyanakurmi mutsapaanakun.

porque se conocen se besan.

(Cordillera de los Andes, Anónimo)

El lamento es otro de los temas recurrentes en el huayno ancashino. El lamento tiene vigencia en hechos y circunstancias que hacen inminentes los alejamientos de parejas por el desengaño, la infidelidad, la correspondencia, la búsqueda de trabajo en otros lugares, entre otros. Así, el lamento es reiterativo como sublimación a su sufrimiento, a su angustia, a su alejamiento. En el texto que sigue, se observa la aspiración al amor plenamente correspondido que se presenta como una triste experiencia por no haberse logrado.

(5) Imapaqraq kuyallarqaa imapaqraq wayllullarqaa mana kuyakuy yachaqta mana wayllukuy yachaqta.

('Te adornara de diamantes', Anónimo)
Para qué habré amado para qué habré adorado a quien no sabe amar a quien no sabe adorar.

Un siguiente eje temático en el huayno ancashino es la soledad que se expresa, principalmente, por el abandono o ausencia del ser querido, por el desamor o por la falta de ese ser que le haga la compañía. Pues, la dualidad es otro de los principios fundamentales en la organización andina expresada en la relación entre el hanaq patsa "el mundo de arriba" y uran patsa "el mundo de abajo", divisiones que a su vez se amplía con la dualidad masculina y femenina el mundo andino (Julca, 2010). Según ello, en el verso que sigue, él o ella no puede vivir solo, no puede dormir porque necesita la presencia de la pareja, el complemento. Esta es una clara manifestación de que el enamorado necesita la correspondencia de la enamorada y viceversa.

(6) Puediitsu, puediitsu,

hapallaa punuyta puediitsu;

tumarillaa, tikrarillaa

mana kaqllamanmi tumarillaa.

('Zorro, zorro', Anónimo)
No puedo, no puedo, dormir solo no puedo; me volteo para un lado y otro, volteo donde tú no estás. 
El erotismo es expresado como una ocurrencia normal que, a veces, se presenta de muy subido de tono irónico y sarcástico. Así, la acción sexual es expresada de una manera natural, e incluso directa aprovechando los recursos expresivos de la lengua quechua (Villafán, 1992; Julca \& Smith, 2005; Julca \& Julca, 2016). Esta es, también, una característica de los hombres del Ande acompañada de la burla, la mofa y la risa ${ }^{5}$. En el texto que sigue se entiende que la pareja se encuentra en una relación sexual y como consecuencia de ella, la muchacha saltaba.

(7) Tsayna tsaynachi

chiinaqa pintirqan

antakashanaw

tuksipa tuksiptin.

('Qatiraykanqaachaw', Anónimo)
Por eso, por eso sería

que la muchacha saltaba

cuando, como la aguja de arriero

la hincaba, la hincaba.

\section{Recursos estilísticos y figuras literarias}

El huayno ancashino es una manifestación del arte verbal quechua. En la composición de las letras del huayno ancashino, los autores, mayormente anónimos, utilizan diferentes recursos estilísticos y figuras literarias similares a los practicados en la literatura oficial académica. En lo que sigue se presenta muestras de uso de las principales figuras literarias como la metáfora, el símil, la aliteración, la onomatopeya, el paralelismo, entre otros y recursos estilísticos como la métrica.

En el siguiente ejemplo se evidencia el uso de la metáfora, donde la palabra-frase palomitallaa 'mi palomita (adorada)' es usada con el significado figurado referido a la mujer amada y no al ave paloma que es su significado literal prístino. Además, es importante observar que palomitallaa es una palabra compuesta: castellano (palomita) + quechua (-llaa). Este sufijo quechua, además de expresar el posesivo de primera persona, expresa diminutivo, pero fundamentalmente, afectividad, cariño, ternura (véase Julca, 2009c; Julca \& Julca, 2016). 
(8) Kananmi waqarishun, waraymi llakirishun; allaw palomitallaa yarpar kedarishun ('Madre querida', Anónimo)
Hoy vamos a llorar, mañana vamos a sufrir; pobrecita mi amada (palomita) recordando vamos a quedar.

El símil como figura literaria es usada en la comparación de ciertos comportamientos humanos con el comportamiento de los animales. Por ejemplo, en el siguiente fragmento se compara al hombre enamorado con el astuto zorro.

(9)

zorro de la puna,

qamtawan nuqata

nuna chikimantsik.

Qamta chikishunki

uushanta apaptiyki,

nuqata chikiman

wawanta suwaptii.

Qamshi kutitsinki

tullunta millwantin;

nuqashi kutitsishaq

wawanta willkantin.

('Zorro, zorro', Anónimo)
Ay, zorro, zorro

zorro de la puna, tanto a ti como a mí

la gente nos odia.

Tú devolverás

su hueso con su lana;

yo devolveré

a su hija con su nieta.

La aliteración es otra de las figuras literarias que es usada como recurso expresivo consistente en la repetición de igual o similares sonidos en diferentes palabras. Esta le da un matiz especial a la musicalidad de la canción-poema en el huayno ancashino. En el siguiente verso se observa la repetición sucesiva del sufijo acusativo - ta y la raíz verbal mantsa-.

(10) Liyunta mantsatsu

tinrita mantsatsu,

tsaytsuraq mantsaaman

kashpi chanka suegraata.
No tengo miedo al león no tengo miedo al tigre, como voy a tener miedo a mi suegra de piernas flacas.

('Liyunta mantsatsu, tinrita mantsatsu', Anónimo) 
La otra figura muy presente en la literatura quechua en general y en el huayno ancashino en particular es el uso de las expresiones onomatopéyicas. En rigor, el quechua registra muchas entradas léxicas provenientes de las expresiones onomatopéyicas propias del mundo andino. Así, por ejemplo, muchos nombres de los animales provienen de sonidos onomatopéyicos producidos por los mismos animales. Por consiguiente, en este tipo de palabras está implícito de la característica predominante del ser nombrado (Julca \& Julca, 2016). En el siguiente ejemplo, la voz onomatopéyica es usada para caracterizar a un ave, pero en ciertas circunstancias también es usada para designar a dicho ave.

(11) Wallpaqa turiq, turiq; $\quad$ La gallina turiq, turiq;

hakaqa wichik, wichik; el cuy wichik, wichik;

chiinaqa dale que dale la muchacha dale que dale

tiyunpa santunchaw. en el cumpleaños de su tío.

('Ciega pasión', Anónimo)

El paralelismo en el huayno ancashino es un recurso literario que consiste en la repetición de estructuras similares (palabra-frases), pero con diferente o parcialmente diferente entrada léxica. La reiteración fonética representa la insistencia o el énfasis sobre aquello que se está diciendo. En el ejemplo que sigue se observa la repetición de la palabra-frase mayllachaw, tsayllachaw y tsaynaku al inicio del verso (anáfora).

(12) Mayllachaw tupashqapis

tsayllachaw, nimankiran.

Tsayllachaw tinkushqapis

tsaynaku, nimankiran.
Cuando nos encontramos en algún lugar allí nomás me vas a decir.

Si nos encontramos allí nomás, ya de una vez, me vas a decir.

('Qatiraykanqaachaw', Anónimo)

Finalmente, la métrica también es usada en el huayno ancashino tradicional. Este recurso consiste en el uso de patrones rítmicos en los versos. Comúnmente, "al medir un verso se cuentan tantas sílabas como haya en la pronunciación real; cada sílaba fonética constituye una sílaba métrica" (Lapesa, 
1976, p. 73). Si bien, la métrica fue una de las características de la poesía española, también este recurso literario está presente en el huayno ancashino. Veamos el siguiente texto:

(13) Ship.shi sha.mur.qaa.tsu, Fi.lli.chii.ta tam.ya kuy.ku.llap.tin, ka.ray; ka.nan. sha.mun.qaa.chaw, Fi.lli.chii.ta ship.shi kaq.llaa.ta.wan, ka. ray ('Te adornara de diamantes', Anónimo)
10 Anoche no pude venir, Felicianita

8 porque cayó la lluvia, caray;

10 ahora que he venido, Felicianita

8 dame lo de anoche también pues, caray.

Como podemos ver, en las composiciones del huayno ancashino, los autores recurren a la métrica como a un recurso estilístico y poético que va acorde con el ritmo de la canción.

\section{Recursos lingüísticos y comunicativos}

En el huayno ancashino se usa diferentes recursos lingüísticos y comunicativos como monólogos y diálogos. Asimismo, se echa mano de los préstamos lingüísticos, alternancia de códigos y mezcla de códigos, estos últimos como consecuencia del contacto prolongado con el castellano. A continuación, se presenta algunos ejemplos representativos.

El monólogo aparece como una autoconfesión, una acción personal íntima y una autorreflexión.

(14) Suertillaachi kallarqan, destinullaachi kallarqan, las doce intinawpis shaykar quedarillaanaapaq, waqar quedarillaanaapaq. ('Plantalla, planta', Anónimo)
Habrá sido mi suerte, habrá sido mi destino, como el sol de las doce para quedarme parado, para quedarme llorando.

En el diálogo, el yo poético finge como un receptor. En este caso, la actitud comunicacional es expresada con oraciones exhortativas e imperativas con destino a la mujer amada, al público o la naturaleza. 
(15) Despachadora despachallaamay hasta el Puente de Calicanto. Tsaypitanachi aywakullaashaq casadawanpis, solterawanpis. ('Despachadora', Anónimo)
Despachadora, despáchame hasta el puente de Calicanto. Desde allí ya me iré con una (mujer) casada o soltera.

Los préstamos lingüísticos, principalmente, léxicos del castellano en quechua y viceversa son abundantes. Las palabras prestadas, algunas veces son nativizadas y; otras veces, tomadas como tales de la lengua fuente. Veamos los siguientes dos ejemplos donde en el primero, el castellano es la lengua fuente y el quechua la lengua receptora, mientras que en el segundo, el castellano es la lengua receptora y el quechua la lengua fuente.

(16) Arusta niptiyki, fidyusta niptiyki pobresallaawan puedillaashaqtsuraq; cumplirte;

shaqwillawanqa, papallawanqa, wiray, wiraychi waatashqayki.

('Marzo tiempo', Juan Rosales)

(17) Mañana pishto mi chancho chunchulin te voy a dar, mañana pishto mi chancho

oqetin te voy a dar.
Si me pides arroz, si me pides fideos, con mi pobreza qué he de poder pero con sopita de harina, con papitas, muy gordita ha de tenerte.

Mañana mato a mi chancho sus intestinos te voy a dar, mañana mato ami chancho su ano te voy a dar.

('Waychaw', Guido Antúnez de Mayolo)

El cambio de código o alternancia de códigos es otro de los recursos lingüísticos y comunicativos. La alternancia de códigos se da de oración a oración como también al interior de una misma oración (inter-sentential e intra-sentential, Winford, 2003). Los mecanismos son variados. Por ejemplo, hay casos donde las lenguas son alternadas verso a verso (18), dos versos a dos versos (19), de estrofa a estrofa (20), así como otras combinaciones (tercera estrofa de 20).

(18) Tengo una vaca barrosa Tengo una vaca barrosa 
ishkaylla wawayuq,

de pura mala cabeza

ishkayta wachanqaran.

('Vaca barrosa', Anónimo)

(19) Ay, zorro, zorro

zorro malagüero,

qamtawan nuqata

nuna chikimantsik.

('Zorro, zorro', Anónimo)

(20) Manam mamaa kantsu,

Manam taytaa kantsu,

mamaa, taytaa karpis

allpapa shunqunchawmi.

La luna es mi madre, el sol es mi padre, $y$ las estrellitas son mis hermanitas.

Haytatsun waqakushun, haytatsun llakikushun,

a pesar de los pesares

kushikur waraarishun.

('Huérfano soy’, Anónimo) que tiene dos crías, de pura mala cabeza dos más ha de parir.

Ay, zorro, zorro, zorro malagüero, tanto a ti como a mí la gente nos odia.

Yo no tengo madre, yo no tengo padre, si tengo madre y padre ellos están bajo la tierra.

La luna es mi madre, el sol es mi padre, y las estrellitas son mis hermanitas.

Cómo vamos a llorar por eso, cómo vamos a sufrir por eso, a pesar de los pesares contentos hay que amanecer.

\section{Discusión}

En primer lugar, el huayno ancashino tradicional es una manifestación poética, artística y literaria que desarrolla diferentes campos temáticos relacionados con la vida del hombre del campo en sus múltiples realizaciones y situaciones de convivencia. Uno de los temas preferidos es el amor en sus múltiples manifestaciones dedicadas, principalmente, a la mujer amada en términos de ruego, añoranza, venganza, sufrimiento, etcétera. Así, las composiciones abarcan diferentes ejes temáticos relacionados con la cultura andina como la concepción de la naturaleza y la sociedad como una unidad (2), (3) y (20); la reciprocidad (4) y (20), la moral andina (1), (11) y (18); el amor se presenta con muchos rostros expresado como lamento (5) y (15); sufrimiento (8), (14) y (19); soledad (6); 
humor (9) y (10); erotismo (7) y (13), sexualidad (7) y (12); perseverancia (16) y venganza (17). Esta pluralidad temática es expresada artísticamente fundada en los grandes valores y principios de la cultura andina. Las características temáticas recurrentes en el huayno ancashino también las encontramos en los trabajos de Den Otter (1985) Rosales (1991, 2009), Villafán (1992), Julca (2009b), Montoya (2013) y Julca \& Julca (2016). Es importante subrayar que el contenido temático de las canciones cambia de canción a canción, pero también pueden cambiar al interior de una misma canción (20). Es decir, las estrofas pueden abordar temas diferentes, por ejemplo, la fuga, por lo general, desarrolla un tema diferente al resto de las estrofas. Por lo tanto, la variedad temática del huayno ancashino se expresa en las canciones e incluso al interior de cada una de las canciones.

En segundo lugar, el arte verbal quechua se expresa utilizando diferentes recursos estilísticos y figuras literarias. La metáfora es una de las figuras literarias más recurrentes en el huayno ancashino, incluso la comunicación cotidiana en quechua está cargada de metáforas (Víctor Paredes, comunicación personal). Por ejemplo, en el tercer verso del fragmento (8), la palabra palomitalla es usada metafóricamente con el significado de mujer amada, dado que en su sentido prístino significa ave. Además, el significado de mujer amada es expresado con mucha ternura mediante el uso del sufijo diminutivo castellano -it(a), reforzado con el sufijo afectivo del quechua -lla, para intensificar aún más el cariño y ternura. El morfema diminutivo y afectivo quechua -lla tiene una marca morfológica y una carga semántica especial que da lugar a la apreciación. Esta marca sirve, entonces, para expresar la afectividad, la cortesía, la cordialidad y el cariño (Julca, 2009c; Julca \& Julca, 2016). En suma, existen diferentes mecanismos gramaticales, léxicos y textuales en el proceso de formación de metáforas en el huayno ancashino están cargadas de humor e ironía que simbolizan la cosmovisión y el pensamiento del hombre andino.

Hurtado de Mendoza (2009) sostiene que la cultura y la lengua quechuas, como cualquier otra lengua natural del mundo, disponen de la metáfora como un recurso de la designación. Mediante las metáforas se establece las comparaciones 
de las cualidades o propiedades de seres humanos, fenómenos, hechos, conceptos o entes en general. Así, en las muestras del huayno ancashino se observa que, según la intención comunicativa, las palabras cambian de significado a partir de su significado literal hasta lograr un significado figurado literariamente. Por ejemplo, en la muestra (7), la palabra antakasha 'aguja de arriero', metafóricamente, significa 'órgano sexual masculino erecto (puntiagudo)'. Así, siguiendo a Godenzzi (2005), podemos concluir que, el huayno ancashino tradicional como una expresión del pensamiento popular andina, aparece fuertemente marcado por equivalencias que son del orden de la metáfora.

Si bien la metáfora es una de las figuras más usadas, también están presentes otras formas estéticas de manifestar mensajes que aparecen en relación con el uso social y cultural de la lengua. Pues, el arte verbal quechua provee significados y recursos como la metáfora (8), paralelismo (12) y manipulación narrativa con diferentes fines: cómico o humorístico, religioso, retórico, comparativo, imitativo. Asimismo, los versos quechuas registran elementos rítmicos donde la combinación de número de sílabas y el acento grave de las palabras le dan un matiz especial prosódico y semántico especial. En el huayno ancashino, las palabras son manipuladas libremente, pero siempre ajustadas a ciertas reglas. El juego del lenguaje como una forma del uso lingüístico cumple varias funciones, psicológica, cultural, humorística y artística o poética (Sherzer, 2002). Al respecto, Chávez (1998, p. 167) refiere que es de entender que todo hombre tiene entre sus necesidades instituir lingüísticamente sus sentimientos de nostalgia y alegría, sus glorias y penurias, como recursos catárticos que lo elevan a las más altas esferas de su humanidad, permitiéndole definirse en su verdadera esencia. La lengua quechua presenta una posibilidad exquisita para el quehacer poético y literario, es una lengua que alcanza sonoridad en la combinación de palabras que se constituyen en cada verso, frase u oración. El uso de sufijos le da una flexibilidad que hace más adecuada a los requerimientos sentimentales y permite construir metáforas, comparaciones y toda clase de figuras literarias. 
En tercer lugar, los recursos lingüístico-comunicativos están relacionados con el uso de monólogos y diálogos, la resemantización de palabras y préstamos lingüísticos, así como la alternancia de códigos. La actitud comunicativa del yo poético se expresa mediante monólogos que son autoconfesionales, intimistas y reflexión para sí mismo $(5,6,10,14)$ y diálogos conversacionales en los que se finge un oyente presente $(1,3,4,15,16 \ldots)$, (Villafán, 1992; Julca, 2009b; Julca \& Julca, 2016). En los diálogos, el yo poético conversa no solamente con personas $(1,4,5,6 \ldots)$, sino también con animales $(2,10,9,11)$, plantas (3) y otros seres (14) como una clara manifestación de la integración hombre-naturaleza de la concepción andina.

La resemantización y los préstamos léxicos son usados como recursos expresivos y comunicativos en el huayno ancashino. Primero, la resemantización de las palabras está asociada, principalmente, a la generación de metáforas y otras figuras literarias. Así, los vocablos palomitallaa (8) y antakashanaw (7) adquieren un significado figurado, muy diferente a su significado prístino: palomitallaa 'mi palomita (ave)' > 'mi mujer amada', antakashnaw 'como la aguja de arriero' $>$ 'como un pene erecto'. Como consecuencia del contacto lingüístico y social prolongado entre las sociedades hispano-occidental y andina, los préstamos léxicos tienen presencia en el huayno ancashino en forma bidireccional, es decir, tanto del castellano en quechua $(6,8,10,11,14,15,16)$ como del quechua en el castellano (17). Segundo, los préstamos léxicos se dan, principalmente, por necesidad antes que por prestigio para expresar poética y rítmicamente los mensajes (véase Campbell, 1998; Thomason, 2001; Julca, 2009b). En general, las palabras prestadas se someten a un proceso de nativización o refonologización que implica someter a las palabras de la lengua fuente a la estructura silábica y morfofonológica de la lengua receptora. Por ejemplo, en (7) y (10), las palabras castellanas puede y león son nativizadas como puedi y liyun, respectivamente, donde las vocales medias y abiertas $\boldsymbol{e}, \boldsymbol{o}$ del castellano cambian a las vocales altas y cerradas $\boldsymbol{i}$ y $\boldsymbol{u}$ del quechua. Además, en el caso de la palabra león, la nativización es mayor dado que la secuencia de las vocales eo es afectada por la inserción consonántica de $\boldsymbol{y}$ (li.yun.ta) debido a que la estructura silábica del 
quechua no permite sílabas con secuencias vocálicas. Asimismo, en los préstamos léxicos del castellano en quechua es frecuente observar que a la palabra base de la lengua fuente se añade sufijos del quechua en conjunción a su carácter de lengua aglutinante de tipo sufijante. Así, a la base léxica puedi- se añade el sufijo de primera persona actora $-i$ y el sufijo negativo -tsu 'no' (puedi-itsu 'yo no puedo'). Del mismo modo, a la base léxica liyun- se añade el sufijo acusativo marcador de objeto directo -ta (liyun-ta 'a el león'). En resumen, la resemantización de las palabras y los préstamos lingüísticos, principalmente, léxicos son usados como recursos lingüísticos, expresivos y comunicativos en el huayno ancashino tradicional.

Finalmente, el cambio de códigos o alternancia de códigos entre las lenguas quechua y castellano es un recurso lingüístico-comunicativo muy usado en el huayno ancashino. En general, el cambio de código es un término paraguas que abarca una variedad de tipos del uso bidialectal y bilingüe del lenguaje como resultado de diferentes circunstancias y motivaciones comunicativas y otros factores sociales como identidad de los interlocutores, tema y formalidad (Winford, 2003; Julca, 2009b). En el caso del huayno ancashino tradicional, el cambio de código está referido al uso de las lenguas quechua y castellano en una misma conversación o declaración (monólogo o diálogo). En otros términos, el cambio de código se refiere a los casos donde los hablantes bilingües alternan códigos o lenguas dentro de un mismo evento de habla (canción: inter-sentential code switching) o incluso dentro de una misma oración (estrofa o verso: intrasentential code switching). En (18) el cambio de código se da de verso a verso (intra-sentential code switching); en (19), de dos versos en dos versos y; en (20) de estrofa a estrofa (inter-sentential code switching) y en la última parte de la tercera estrofa de verso a verso (intra-sentential code switching), (Ibíd.). Por tanto, el uso de una lengua u otra en el huayno ancashino está en función del tema, situaciones y hechos que quieren comunicar los interlocutores (yo poético); asimismo, cómo quieren comunicar dichos temas: con ternura, súplica, insulto, entre otros. 


\section{Conclusiones}

El quechua como toda lengua natural del mundo tiene suficientes recursos expresivos, literarios y lingüístico-comunicativos. Así, en el huayno ancashino tradicional, el quechua registra rasgos lingüísticos universales de igual o similar consistencia que otras lenguas de prestigio para transmitir no solo lingüísticamente, sino también estética y literariamente los elementos linguoculturales del pueblo andino. Por consiguiente, el quechua permite la elocuencia, los juegos de palabras, los procedimientos retóricos; la excelencia estética de los mensajes como se evidencia en el huayno ancashino.

El huayno ancashino tradicional desarrolla una gran variedad temática relacionadas con la vida del hombre del campo en sus múltiples realizaciones acorde a la concepción cultural andina. En dicho marco, uno de los temas preferidos es el amor que se expresa en sus múltiples facetas como: la soledad, el abandono, el lamento, el sufrimiento, la venganza, el humor, el erotismo y la sexualidad, entre otros. En las canciones se usan diferentes recursos estilísticos, poéticos y figuras literarias. La metáfora es la figura literaria más recurrente, pero también se usan el símil, paralelismo, aliteración y onomatopeya. Asimismo, la métrica aparece en las composiciones para evidenciar el ritmo de las canciones. En adición, los recursos lingüístico-comunicativos se expresan con el uso de monólogos y diálogos, resemantización de las palabras, préstamos léxicos y alternancia de códigos.

Finalmente, el quechua es un idioma literario, completo y admirable, semejante a todos los idiomas del mundo con o sin tradición escrita; es maravilloso, tanto por la riqueza de sus expresiones literarias y modalidades lingüísticas cuanto por el valor y naturaleza de sus raíces; es notable, por su inmutabilidad morfológica y semántica, por su extraordinaria peculiaridad generativa de nuevas palabras mediante la sufijación, así como por el mecanismo de sus fonemas y morfemas yuxtapuestos en la estructura gramatical. 


\section{Notas}

1 José María Arguedas, afirma: "el indio sabe expresar sus sentimientos en lenguaje poético; demostrar su capacidad de creación artística y hacer ver lo que el pueblo crea para su propia expresión, es arte esencial. (...) Los que hablamos este idioma sabemos que el kechwa supera al castellano en la expresión de algunos sentimientos que son los más característicos del corazón indígena: la ternura, el cariño, el amor a la naturaleza. (...) El kechwa logra expresar todas las emociones con igual o mayor intensidad que el castellano. (...) El kechwa es un idioma suficientemente rico para la expresión del hombre superior. En circunstancias propicias podrá dar una gran literatura" (1986, p. 28-30).

2 En general, el estudio del huayno ha merecido la atención de artistas, folcloristas, etnomusicólogos, antropólogos, entre otros. Dichos estudios acerca del huayno se han concentrado mayormente en el aspecto musical (rítmica, armonía, melodía), la danza y los procesos evolutivos de cambio que lindan entre lo tradicional y lo moderno (véase Den Otter, 1985; Romero, 1985; Vásquez y Vergara, 1990; Roel, 1990; Carrasco, 2003; entre otros). No obstante, Mendívil (2004) señala que "se puede observar al huayno como un fenómeno social y no solo como una pieza musical con determinados patrones melódicos o rítmicos" (p. 37). Por nuestra parte, consideramos el estudio del huayno, además de su concepción y estudio como música, danza y fenómeno social, también amerita una mirada y análisis del uso del lenguaje desde la perspectiva linguo-literaria.

3 Las nuevas generaciones practican el huayno moderno o híbrido interpretado mayormente en castellano con contenidos temáticos que escapan al mundo cultural andino. Asimismo, se observa cambios notorios en la armonía, en la rítmica y en la melodía. Los innovadores usan instrumentos musicales electrónicos modernos (órgano, arpa, guitarra eléctrica, baterías electrónicos), se presentan con bailarinas con diminuta vestimenta, etcétera. En dicho proceso, han surgido mixturas como los huaynos 'híbridos' que han incorporado elementos de la cumbia e, incluso, del rock (véase Mendívil, 2004 y Zevallos-Aguilar, 2016). Al respecto, Carrasco (2003) refiere que los géneros musicales han sufrido muchos cambios; en dicho proceso, los innovadores han realizado adecuaciones, renovaciones y reinventos para los tiempos actuales con la finalidad que prosiga así su vigencia en el gusto de las nuevas generaciones. Por consiguiente, como refiere García (1995), los cambios se dan "como referente histórico y recurso simbólico contemporáneo" (p. 257).

4 Anita Fajardo, siguiendo a la canta-autora Estrellita de Pomabamba, hoy ha popularizado a nivel regional y nacional, el chimaychi, una de las variedades del huayno ancashino que se canta y baila en la zona norte de Conchucos, principalmente, en Pomabamba.

5 Ortiz (1997, p. 335), al analizar los cantos quechuas de Arguedas, afirma que dichos cantos referidos a los amores bucólicos utilizan metáforas en que se describe las aventuras como salvajes y silvestres.

\section{Referencias bibliográficas}

Arguedas, J. M. (1940, agosto 18). Canción popular mestiza e india en el Perú, su valor documental y poético. En La Prensa, Buenos Aires. 
Arguedas, J. M. (1986). Cantos y cuentos quechuas. Tomos I y II. Lima: Municipalidad de Lima Metropolitana, Munilibros.

Bendezú, E. (2003). Literatura quechua. Lima: Universidad Ricardo Palma.

Campbell, L. (1998). Historical linguistics. An introduction. Edinburgh: Edinburgh University Press.

Carrasco, R. (2003). Apuntes sobre el huayno en el Perú. Recuperado de http:// www.vientoslatinoamericanos.com/archivos/artículos/huayno.html

Chávez, A. (1998). Lingüística quechua. Letras, 69(95-96), 161-170.

Cornejo, A. (1994). Escribir en el aire. Ensayo sobre la heterogeneidad sociocultural en las literaturas andinas. Lima: Editorial Horizonte.

Den Otter, E. (1985). Music and dance of Indians and mestizos in an Andean valley of Peru. Delft: Eburon.

Escobar, G. y Escobar, G. (1981). Huaynos del Cusco. Cusco: Garcilaso.

Espino, G. (2010). La literatura oral o la literatura de tradición oral. Lima: Pakarina ediciones.

García, N. (1995). Culturas hibridas. Estrategias para entrar y salir de la modernidad. Buenos Aires: Editorial Sudamericana.

Godenzzi, J. (2005). En las redes del lenguaje. Cognición, discurso y sociedad en los Andes. Lima: Universidad del Pacífico.

Guamán Poma de Ayala, F. ([1614] 1998). Nueva crónica y buen gobierno. Vol. 3. Edición de J. Szeminski y F. Pease. México D. F.: Fondo de Cultura Económica.

Hurtado de Mendoza, W. (2009). Metáfora y pensamiento de la cultura quechua. Lima: Asamblea Nacional de Rectores.

Instituto Nacional de Cultura. (1980). Cancionero popular huaracino. Cuadernos de difusión $N^{\circ} 29$. Huaraz: INC-Huaraz (Mimeo).

Itier, C. (1999). Literatura nisqap qichwasimipi mirayñinmanta. Amerindia, (24), 31-45.

Julca, F. (2009a). Lengua y sociedad andina. Lima-Carhuaz: Urpichallay, Gráfica Líder. 
Julca, F. (2009b). Word borrowing and code switching in Ancash waynu songs. En Sunakawa C. y Edwards, T. (eds.). Language Meaning and Society. Vol. 2, 69-95.

Julca, F. (2009c). Quechua Ancashino: una mirada actual. Lima: CARE Perú / Fondo Editorial del Pedagógico San Marcos.

Julca, F. (2010). Diversidad cultural y la educación superior en Áncash. Inclusión social y equidad en la educación superior. Revista ISEES, (7), 115-130.

Julca, F. (2015). Hacia la dignificación del quechua: desmitificando falacias y prejuicios lingüísticos. Revista Académica UNASAM, (2), 46-70.

Julca, F.; Espinoza, F. \& León, H. (2008). Chawpi qichwata alli qillqanapaq maytu. Manual de escritura del Quechua Central. Lima: Ministerio de Educación.

Julca, F. \& Julca, C. (2016). Quechua: riqueza léxica y expresiva. Lima: INADEA / Killa editorial.

Julca, F. \& Smith, W. (2005). Perspectives on indigenous humor: a comparative study of humor in Ancash Quechua waynu songs and Kuna riddle-like jokes in colloquial speech. Austin, Estados Unidos: University of Texas at Austin (Ms).

Lapesa, R. (1966). Introducción a los estudios literarios. Salamanca: Ediciones Anaya.

Lira, J. (1982). Diccionario kkechuwa-español [2a Ed.]. Bogotá: Secretaría Ejecutiva del Convenio Andrés Bello.

Maguiña, S. (s.f.). Cancionero popular folklórico ancashino. № 5, 6 y 7. Huaraz: Imp. La Hoja.

Mendívil, J. (2004). Huaynos híbridos: estrategias para entrar y salir de la tradición. Lienzo, (25), 27-64.

Montoya, R. (2013). Encanto y celebración del wayno. Cusco: Dirección Regional de Cultura Cusco.

Ortiz Rescaniere, A. (1997). La metáfora de los amores salvajes en el 'Canto Kechwa' de José María Arguedas. Antropológica, 15(15), 355-369. Recuperado de http://revistas.pucp.edu.pe/index.php/anthropologica/ 
article/view/1230

Parker, G. (1972). Falacias y verdades acerca del quechua. En Escobar, A. (Comp.). El reto del multilingüismo en el Perú. Lima: Instituto de Estudios Peruanos, 111-121.

Roel, J. (1992). El wayno del Cusco. Cusco: Municipalidad del Qosqo.

Romero, R. (1988). La música tradicional y popular. En La música en el Perú. Lima: Patronato Popular y Porvenir Pro Música Clásica, 215-283.

Rosales, E. (1991). Canto del cuculí encendido. Antología de la poesía popular ancashina. Trujillo: Editorial Libertad EIRL.

Rosales, E. (2009). Canto del cuculí. El huayno: la expresión cultural andina. Lima: Instituto de Desarrollo Gerencial.

Sherzer, J. (2002). Speech play and verbal art. Austin: University of Texas Press.

Thomason, S. (2001). Language contact. An introduction. Washington D. C.: Georgetown University Press.

Toro, C. (1990). Manual de literatura peruana. Lima: AFA ediciones.

Vansina, J. (1968). La tradición oral. Traducción Miguel Llongueras [2a Ed.]. Barcelona: Editorial Labor.

Vásquez, Ch. y Vergara, A. (1990). Ranulfo, el hombre. Lima: Centro de Desarrollo Agropecuario.

Villafán, M. (1992). Valores de la canción popular bilingüe quechua-español en la región Chavín, Perú. Ponencia presentada en el Tercer Encuentro Nacional de Escritores en Lenguas Indígenas. Ixmiquilpan, Hidalgo, México. (Ms.).

Westphalen, Y. (2019). Antonio Cornejo Polar y la república mundial de las letras. Letras, 90(131), 277-288. doi: 10.30920/letras.90.131.13

Winford, D. (2003). An introduction to contact linguistics. Malden: Blackwell Publishing.

Zevallos-Aguilar, U. (2016). José María Arguedas y la música novoandina: su legado cultural en el siglo XXI. Cuadernos de Literatura, 20(39), 254269. doi: 10.11144/Javeriana.cl20-39.jmam 